\title{
Assessing the safety of gas installations in buildings
}

Received: 8th August, 2005

\section{Barrie Church and Geoff Winckles}

are directors of Global Energy Associates Ltd (GEA), specialist gas engineering consultants providing technical support and tailor-made training courses in the UK and internationally. GEA also produces a simple computer tool to assist with pipe sizing calculations as well as a range of purging units to simplify purging and decommissioning jobs. Both authors are extremely active in the development of UK and European installation standards. This paper represents an updated version of a talk previously given by them to the Continuing Professional Development Foundation in London.

\begin{abstract}
In general, the public perception of natural gas is that it is a safe and reliable product to use for heating premises. Very few realise how widely it is used in commerce and industry, primarily because they rarely hear of an incident or explosion caused by gas. Nevertheless, the risk of an incident will always be present to a greater or lesser extent. The safety of gas installations is of paramount importance to owners and managers of buildings. Previously British Gas and now The Institution of Gas Engineers and Managers (IGEM) and the Health and Safety Executive (HSE) spend a great deal of time and effort to ensure that adequate safety advice is available to designers and installers of gas systems. The lack of major incidents due to gas explosions caused by failures downstream of the meter can only reflect well on competent workmanship and adherence to codes of practice, plus qualified advice available from consultants. Nonetheless, incidents do occur and the most common of these is carbon monoxide poisoning from an appliance or flue problem. A small number of explosions also occur due to gas leakage from pipework within buildings. These can be very photogenic and consequently always make bigger headlines. This paper outlines some of the areas of responsibility for gas installations and guidance for building designers.
\end{abstract}

\section{Keywords:}

explosions, pipework, risk assessment, gas installations, gas safety, building safety

Global Energy Associates Ltd St. Johns House

St. Johns Industrial Estate Dunmow Road, Takeley Bishop's Stortford CM22 6SP, UK

Tel: +44 (o) 1279870710 Fax: +44 (o) 1279870710

E-mail:

barrie.church@globalenergy.co.uk

\section{GAS EXPLOSIONS}

Mixtures of gas and air will burn, but only within limits. If there is either too much gas or too much air, the mixture will not burn. The 'flammability limits' are those air and gas mixtures at each end of the range which will just burn. At the air-rich end it is known as a lean condition and this is the lower flammable limit (LFL) or lower explosive limit (LEL). At the other end where there is too little air it is gas rich and known as the upper explosive limit (UEL) or higher flammable limit (HFL) (Figure 1). 

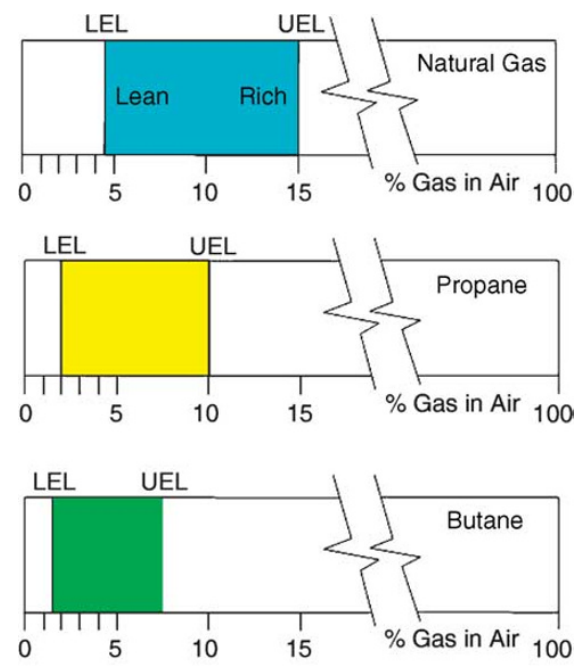

Figure 1: Flammability limits of gas/air mixtures

\section{Conditions for a gas explosion}

For natural gas the flammable range is about $4.5-15$ per cent gas in air, for propane it is $2-10$ per cent and for butane it is $1.8-8$ per cent. As a rough guide, burner gas/air mixtures work at the upper end of the scale and gas leaks build up the air/gas mixture from the lower end, so explosions tend to occur from gas leaks and burning (flames) of the richer mixtures.

If ignition of the gas/air mixture occurs in the open air, and the combustion process is fast enough, a pressure wave may be generated which travels ahead of the flame, at or just above the speed of sound, related to the flame speed of the gas. For natural gas (methane) this is comparatively slow at $0.36 \mathrm{~m} / \mathrm{s}$.

Most releases of gas result from a gas leak and occur within a room or building. If a flammable mixture forms and is ignited then a confined gas explosion will occur (Figure 2).

Under a completely constrained condition, a gas/air mixture can produce a maximum pressure in excess of 8 bar. Most buildings and heating plant are not capable of withstanding anything this high; however,

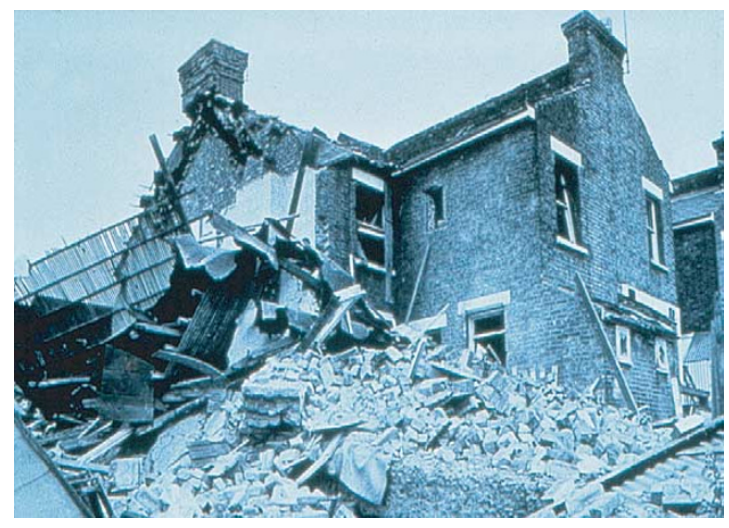

Figure 2: Example of a gas explosion 


\section{Choose materials for strength}

Commercial gas users must prepare a risk assessment internal gas explosions rarely cause complete destruction because, either by design, or fortuitously, the pressure is relieved (vented) in some way.

Buildings tend to be composite structures and in an explosion the weaker parts will fail first, providing an open area venting the pressure. If failure of the weakest structural component is not enough to prevent the explosion pressure increasing, other components will fail in order of strength. This carries on with higher pressures being generated until the total pressure can be vented.

Building Regulations provide guidance on the minimum thickness of glass for a given surface area; the bigger the area the thicker the glass. Typically for a domestic building 20-70 mbar breaking pressure is expected. Domestically it is 'usual' that the windows represent the external weak point of the structure and are the first component to fail and relieve the pressure created by an explosion. Tests carried out some years ago indicate that double glazing only increases the breaking pressure by 30 per cent and shatter resistant films have a negligible effect on breaking pressure.

Light internal walls such as plasterboard and breeze block and internal doors will only withstand around a 50 mbar pressure rise. Traditional 4.5inch brick walls are stronger and withstanding pressure of $200+$ mbar would be usual. Buildings in the UK are not built with explosions in mind, unlike countries that need to protect against earthquakes, it is therefore important that architects do not regard the gas installation as an afterthought.

\section{AREAS OF RESPONSIBILITY FOR GAS INSTALLATION}

All 'persons' working on gas installations within domestic or commercial buildings, under the Gas Safety (Installation and Use) Regulations, must be qualified under the ACS Scheme and CORGI registered. This is neither a cheap nor an easy process.

Codes of practice, in general, express the view that designers need to be competent, however, there is no such legal requirement (other than a duty of care) for anyone on the design side to be qualified to the CORGI level of installers or even to have knowledge of installation standards. The CORGI-registered engineer becomes responsible when he installs/commissions the installation. The contractor only has two real options, one is to complete the work and refuse to commission it and the other is to refuse to start until the design is correct. It is always better to design it right than to have to retrofit it right later. The authors have real experience of architects and mechanical engineering companies making major mistakes in design that could have led to an incident or, at least, unsatisfactory appliance operation.

It has always been the responsibility of all nondomestic gas users (owners or occupiers) to understand the ways in which gas is used on their premises and to have carried out a risk assessment in order that any operational hazards can be identified, controlled and/or removed. This requirement is now part of UK legislation known as the Dangerous Substances and Explosive Atmospheres Regulations 
(DSEAR) resulting from a European Directive known as ATEX.

DSEAR applies to all industrial and most commercial gas and oil-fired installations with exceptions for domestic gas installations and CE-marked gas appliances.

With new plant, the responsibility rests with the final supplier (main building contractor) to ensure that an appropriate level of information is provided to the installer and end user so that, in the first instance, the equipment is safely installed and, in relation to the end user, safely operated and maintained. This information must ensure that a sound basis for safety is available for incorporation into a risk assessment to be carried out by the end user.

With existing plant the user must carry out their own risk assessment and any risks identified must be dealt with by 2006. In all cases the designer/installer/end user is required to show that whatever means is adopted to comply with the DSEAR is justified by risk assessment.

\section{Fundamental design}

Natural gas is lighter than air, unlike LPG, which is heavier than air. So on the basis of safety it is logical that natural gas ventilation must always be at a high level to deal with gas leaks. No gas pipework or appliance should be installed without adequate ventilation.

\section{Gas pipework}

Gas installation pipes and final connections need to be installed in accordance with The Institution of Gas Engineers and Managers' (IGEM)

Pipework needs to meet gas codes of practice

\section{Ventilation is necessary for all pipework areas}

(1994) publication UP/2, Gas Installation Pipework, Boosters and

Compressors in Industrial and Commercial Premises, and tested to UP/1 or 1A. UK legislation Gas Safety (Installation and Use) Regulations (GSIUR) requires pipework to be installed in a sound and workmanlike manner and to be constructed of materials suitable for the purpose. Gas pipework must not be installed in poorly or nonventilated areas, particularly pipe ducts or joint service risers. Unventilated spaces would constitute an 'at risk' situation.

\section{Pipework in service ducts}

Steel gas pipes preferably should be installed within a rising duct ventilated at the top and bottom. On each floor there are often smoke vents that are normally closed (sealed sufficiently to meet fire officer requirements). In the event of a fire (smoke) the vent or vents will open to clear the smoke.

Ventilation cannot be provided using air which is, or can be, distributed around the building. The worry of pipes in ducts is that of leakage from joints, this can be minimised by having as few joints as possible, preferably welded, or an alternative would be to use continuous stainless steel flexible pipe (BS 7838) with fittings outside the duct.

IGEM's (1994) publication UP/2 includes a formula relating to duct ventilation that can be applied to roof or ceiling voids. The installation of gas pipes in large area voids is usually dealt with by using a 'notional' duct around the pipe, so (both) ventilation grilles to the outside preferably 
It's easier to design it right than replace the pipework

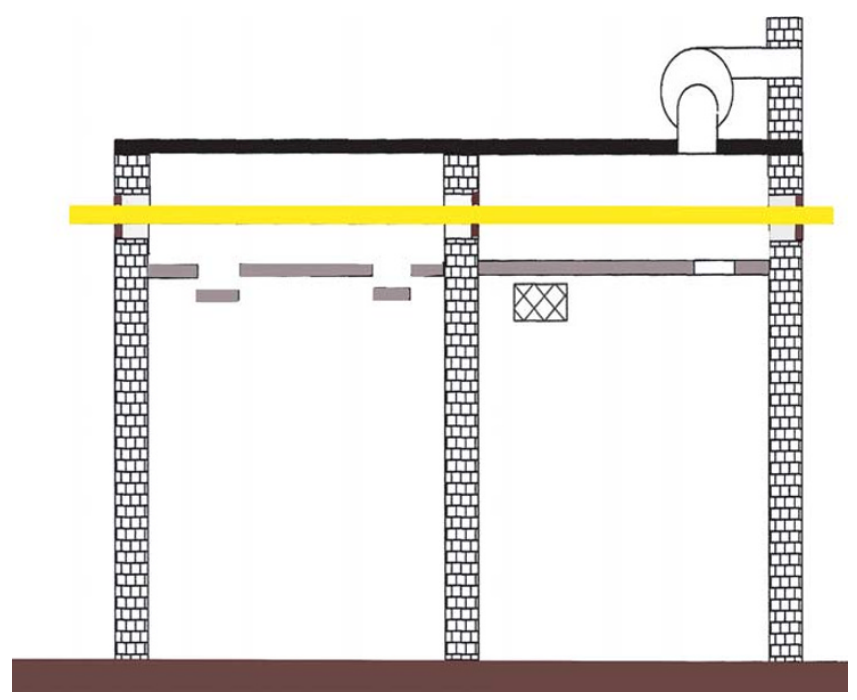

Figure 3: Installation of gas pipes in roof or ceiling voids

would be at a high level and above the pipe for natural gas, to disperse any gas leaks (Figure 3).

\section{Pipe sizing}

The sizing of gas pipework has proven in recent times to be a headache. There is also a lack of understanding of the pressure losses across some types of valve, especially across fire valves, and check meters. Full bore ball valves probably have the lowest pressure drop alongside gate valves; the ball valve has a 90-degree action with easy to see open and closed positions and the other is multi-turn with leakage potential from stem seals with the additional worry of debris preventing tight closing. A cheap alternative at the larger sizes is the butterfly valve but, at low pressures, the pressure drop can be high.

In IGEM's (1994) publication UP/2 it is recommended that for lowpressure installations a 1 mbar total drop from the meter to the appliance isolation valve is aimed for. The addition of an automatic safety shutoff valve (commonly called a fire valve) into pipework could have disastrous effects on pressure drops. Equally, adding a check meter for energy monitoring can prove problematic. The diaphragm meter will have in excess of 1 mbar at maximum rating and a turbine meter may have over 2 mbar. Adding a meter and a couple of valves to a system could reduce the available pressure to below 10 mbar.

\section{Example 1}

In a recent installation, where check meters were installed into existing pipework, the total drop across the system had grown to 10 mbar. This situation was initially blamed on Transco, of course, for lack of pressure. Increasing the Transco inlet pressure was too expensive, as was replacing $80 \mathrm{~m}$ of $150 \mathrm{~mm}$ pipe, and the only solution was to take the components out of line. 


\section{Example 2}

The designer first had underestimated the pipe sizing for the load, making a potentially excessive pressure drop at the required gas rate. This was not discovered until after the pipework was installed.

The mechanical and electrical (M\&E) consultant's solution was to install a gas booster rather than replace a small length of pipe, about $20 \mathrm{~m}$ of $75 \mathrm{~mm}$ diameter, which could be increased in size to $100 \mathrm{~mm}$.

The booster was required to operate continuously and as such a standby was needed. With gas boosters that operate under low or no-load conditions the gas will start to get hot and this in turn could lead to shaft seal failure. So $20 \mathrm{~m}$ of $50 \mathrm{~mm}$ diameter pipe as a cooling loop was needed. The booster room was in the middle of the building and as such mechanical ventilation was needed. Failure of this ventilation might have led to a build-up of gas should there have been a leak; as the system was totally unmanned, so gas detection was also fitted. Correct design initially would have prevented this situation.

\section{Ventilation is always required for gas plant}

\section{Plant-room ventilation}

An assessment should be carried out of potential leakage sources (joints, component appliance pipework, vents etc) and the likelihood of a leak and its consequences. For example, a leak in a basement boiler house would have more consequential concerns than one in a single-storey plant room. Any area assessed as having a 'risk' would need to have some action taken, such as regular checks on pipework tightness, regular visits by staff aware of gas risks and, in extreme cases, gas detection systems installed.

In the case of a basement boiler house one might consider the risk of gas leakage leading to an explosion from threaded, flanged or compression joints, from valve stems, from damaged flexibles or from gas booster shaft seals. In each case the authors would use some knowledge or historical experience of failures and apply a method to monitor and prevent their occurrence. Prevention may be the use of a trained boiler operative to check daily that there is no smell of gas, or to check monthly with a gas leakage tester that there is no indication of gas leakage, or to annually check with leak detection fluid, or to do a pressure tightness test every five years. If none of these simple and mostly low-cost alternatives can be employed one may wish to consider an automatic gas detection system. Whatever automatic or manual system is applied, it will also have risks of system failure. Will the operator forget to do it? Will the detector be unreliable and be overridden?

\section{Example}

There was an incident in a below-ground boiler house, some years ago, that led to a major explosion and severe damage to a high-rise building. Fortunately there were no serious injuries or fatalities as it happened at 01:30am. Rubble was strewn over a playing field that could have killed many children if it had happened during the day. The force was such as to propel slabs of concrete weighing over 1 tonne onto the roof of the 


\section{Design out gas detectors}

\section{The silent killer}

22-storey building. It was considered by the HSE that a greater use of risk assessment should have been used in determining the safety issues relating to the location and maintenance of large plant. Within a few months, IGEM had prepared a draft document on boiler houses (UP/10) dealing with these issues.

\section{GAS DETECTION}

Insurers and architects often consider the use of gas detection systems in commercial buildings. In the authors' experience, gas detection is fraught with problems and best designed out. Such systems, of course, need regular maintenance and calibration but above all the location of the detector heads needs better consideration than is given in current standards.

Where is the best place to locate a detector head in a plant room? Generally, they are located at ceiling level, as natural gas is lighter than air. But in most plant rooms there is plenty of air movement, all of which rapidly dilutes any gas leak. This means that the leak has to be much larger before it is detected unless a more sensitive detection system is applied at greater cost. It would be better to locate the heads nearer to the potential point of gas leakage, but if one knows by risk assessment where a leak may occur, why not design it out?

\section{APPLIANCE INSTALLATION}

\section{Location}

Appliances should be located in a safe and secure position where they will not be damaged by other activities. The use of a purpose-built plant room is preferred. Safe access needs to be made available for maintenance to burners, controls, etc. For example, safe access is necessary at flue (combustion) gas sampling points. Plant rooms and areas adjacent to an appliance should be kept free of combustible materials and any obstructions. The Building Regulations for England and Wales must be applied, and most elements of construction and insulation need to have at least a 30-minute fire integrity.

\section{Carbon monoxide risks}

Air is required for complete combustion and an adequate air supply is essential. This is clearly reflected in IGEM UP/10 for boiler houses where high-level ventilation is always required as high as is practicable and above 85 per cent of the height of the plant room. Similarly, LPG ventilation has to be within $250 \mathrm{~mm}$ of the floor.

There is also a balance between the levels of $\mathrm{CO}_{2}$ and $\mathrm{O}_{2}$ and the production of carbon monoxide (CO). High levels of $\mathrm{CO}$ are wasteful of fuel and may have the potential to cause very serious harm to the heat exchanger surfaces within the appliance or to people if the flue products can leak into occupied areas. If the flue is working fine and the appliance is producing copious quantities of $\mathrm{CO}$, technically there is not a problem as it is all going up the flue. If the flue also fails to operate, however, there is potential for a fatality. 


\section{PREPARING A RISK ASSESSMENT}

There are several ways of preparing a risk assessment and no one system is better or worse than another. It all depends on what one wants from the assessment and how it is to be applied. Some of these techniques are complicated to use for small installations and the HSE (1999) booklet INDG 163 provides, in the writers' view, a more practical analysis.

\section{Risk assessment made easy} The basic steps as given in HSE INDG 163 are:

— Look for the hazard, classify or identify it.

- Decide who or what may be harmed and how.

- Evaluate the risks arising from the hazards and determine whether the existing precautions are adequate or if more should be done. This includes identifying risk control measures, a determination of the risk, an assessment of the significance of the risk and the preparation of a control plan to reduce the risk.

It is vital, however, that plant and procedural risk assessments are reviewed from time to time and especially when any change to the design or operation takes place. One of the main strengths of performing a risk assessment during the design stage is that it highlights potential future problems and enables the designer to consider simpler and often cheaper options. For example, welding or using jointless gas pipe (eg Tracpipe) would probably be cheaper than installing gas detection systems. Using polyethylene pipe below ground overcomes corrosion problems. Selecting a burner that operates on low-pressure gas may be better than using one with a gas booster which has leakage potential, maintenance and power costs.

IGEM is producing a set of generic risk assessments (IGEM/G3) to be used by gas consumers and contractors to take some of the mystique out of the problem. Many of the solutions are based upon those prepared by Global Energy Associates and have been taken from the many assessments produced for its clients. At higher pressures, it may well be that the use of Zone 2 electrical equipment will become the norm and only in special cases might gas detection be vital.

\section{CONCLUSIONS}

Designers, architects and M\&E engineering companies need to have an understanding of appropriate standards and safety procedures or need to use qualified gas consultants who can advise them. Institutions, trade associations and specialised training establishments often run seminars explaining the background and implications of current and new codes of practice.

Failure of professionals to keep ahead of the game exposes them to litigation of all sorts or, worst of all, sees them recommending to clients that money is spent on unnecessary, so-called safety features just not intended by legislators or standards panels. Safety regulations and codes of practice are continuously changing and it is hard for smaller companies to keep up to date. Keeping current is made the more difficult as 
changes are also being driven from Europe within EN standards and there is a real need to be able to monitor new BSs and ENs. Affiliation to (or Associateship with) IGEM is one way to keep up to date. Time and cost are always concerns but keeping up to date is a real safety issue and failure to do so would be hard to explain in court should an incident occur.

\section{References}

Health and Safety Executive (HSE) (1999) 'Five steps to risk assessment — INDG', available at: www.hse.gov.uk/pubns/indg.pdf.

The Institution of Gas Engineers and Managers (IGEM) (1994) UP/2, Gas Installation Pipework, Boosters and Compressors in Industrial and Commercial Premises. IGEM, Loughborough, UK. 